\title{
A Brief Review on Salmonellosis in Poultry
}

\author{
M. Geetha* and K.M. Palanivel \\ Department of Veterinary Preventive Medicine, Veterinary College and Research Institute, \\ Namakkal, Tamil Nadu-637 002, India \\ Tamil Nadu Veterinary and Animal Sciences University, Chennai-51, Tamil Nadu, India \\ *Corresponding author
}

\begin{abstract}
A B S T R A C T
Keywords

Salmonellosis, Poultry

Article Info

Accepted:

10 April 2018

Available Online:

10 May 2018

Salmonellosis caused by Salmonella spp., a gram negative bacterium, is an important disease of poultry all over the world. Salmonella gallinarum $(S$. gallinarum) and Salmonella pullorum (S. pullorum) are avian host specific Salmonellae which causes fowl typhoid and pullorum disease in poultry and they are transmitted in between birds by both vertical and horizontal transmission. This article briefly reviews about epidemiology, clinical signs, diagnosis of avian salmonellosis.

\section{Salmonellosis}

\section{Definition}

Salmonellosis caused by Salmonella spp., a gram negative bacterium, is an important disease of chicken all over the world. Avian host specific salmonellae include Salmonella gallinarum ( $S$. gallinarum) and Salmonella pullorum ( $S$. pullorum) which causes fowl typhoid and pullorum disease (Rajagopal and Mini, 2013) respectively.

\section{Occurrence}

\section{Global scenario}

Fowl typhoid and pullorum disease are distributed in many countries of the world,

and have economic significance (Barrow et al., 1992). They are mainly distributed in Latin America, the Middle East, Africa and perhaps other parts of the world (Bouzoubaa et al., 1992; Shivaprasad, 1997). Salmonellosis has also been reported in many countries of South-East Asia including Bangladesh (Bhattacharjee et al., 1996), India (Saha et al., 2012), Nepal (Jha et al., 1994) and Pakistan (Javed and Hameed, 1989).

\section{Indian scenario}

Salmonellosis is a hyperendemic disease in India affecting both man and animals (Kumar et al., 1997). From 1996 to 2008, fowl typhoid was diagnosed several times in India, but pullorum disease was reported once during 2002 (Barrow and Freitas Neto, 2011).
\end{abstract}


Over all prevalence of avian salmonellosis was 2.7 per cent in Uttar Pradesh (Menghistu et al., 2011). Although, Indian poultry industry is evolving and emerging as the world's second largest market, fowl salmonellosis is increasingly rampant if not endemic with a huge bearing on the economy as well as the future development of poultry sector. There is relatively less number of reports of salmonellosis from India despite its high prevalence, which can be attributed to limited diagnostic facilities under field conditions and underreporting (Rajagopal and Mini, 2013).

\section{Tamil Nadu}

Assessment of carrier status of $S$. Pullorum and S. gallinarum infection in healthy flocks of chicken found to be 16 per cent of positivity from northern part of Tamil Nadu by rapid serum agglutination test (Selvam et al., 2010).

A total of 23 Salmonella enterica subsp. enterica isolates were obtained while screening of poultry tissue samples including liver, yolk, ovary, intestinal contents, spleen and pooled organs collected from layer farms in and around Namakkal, Tamil Nadu, India during 2010-11 by Saravanan et al., (2012).

\section{Epidemiology}

\section{Agent}

Salmonella are gram negative, short plump shaped rods, non - spore forming, non capsulated, aerobic and facultative anaerobic organisms and classified under the family Enterobacteriaceae (OIE, 2006). More than 2300 serotypes of Salmonella have been identified, only about 10 per cent of these have been isolated from poultry (Gast, 1997a). Currently over 2500 serovars are recognized (Grimont and Weill, 2007).
The most important pathogenic members of avian salmonellosis include Salmonella enterica subsp. enterica serovar Gallinarum and Salmonella enterica Subsp. enterica pullorum (Nazir et al., 2012). There are host specific and represent a major concern for the poultry industry causing fowl typhoid and pullorum disease (Rosu et al., 2007) respectively.

\section{Host}

Pullorum disease is usually confined to the first 2-3 weeks of age in chicks and occasionally occurs in adults (Shivaprasad, 1997). Historically, Fowl typhoid was thought to be primarily a disease of growing and adult chickens and turkeys, whereas pullorum disease was primarily a disease of chicks and poults. However, growing and mature chickens and turkeys are probably most susceptible to fowl typhoid (Shivaprasad, 2000).

\section{Epidemiological measures of causal association}

\section{Age}

Age wise prevalence of avian salmonellosis showed highest infection rate in adult layers $(53.25 \%)$ in comparison with brooding $(14.55 \%)$, growing (16.10\%) and pullet (16.10\%) (Rahman et al., 2004). Salmonellosis outbreaks were recorded maximum at the age of 7-9 days, while the mortality was found in chickens of 1-2 weeks of age (Rajagopal and Mini, 2013).

\section{Breed}

White leghorns appear to be more resistant than heavy breeds such as Rhode Island Red, New Hampshire, or crosses between the two (Hutt and Crawford, 1960). Significant differences also exist in susceptibility to 
pullorum disease among chicken (Bumstead and Barrow, 1993).

\section{Management}

Persistent Salmonella infection in the poultry farms mainly by contaminated day old chicks and feed (Oystein et al., 1996).

\section{Clinical signs}

Clinical signs in fowl typhoid and pullorum disease in chicks and poults include moribund and dead birds in the incubator and affected birds may manifest depression, somnolence, anorexia, huddling together, droopy wings, dehydration, laboured breathing, diarrhoea, ruffled feathers, weakness and adherence of faeces to the vent (Shivaprasad, 2000).

Clinical signs of fowl typhoid and pullorum disease may not be apparent in some cases and non specific clinical signs including a decline in feed consumption, a droopy appearance, or ruffled feathers and pale and shrunken combs may be observed (Shivaprasad, 2000).

\section{Gross lesions}

Gross lesions due to fowl typhoid and pullorum disease in chicks and poults include hepatitis, splenitis, typhilitis, omphalitis, myocarditis, ventriculitis, pneumonia, synovitis, peritonitis and opthalmitis. In mature fowl, lesions include oophoritits, salphingitis, orchitis, peritonitis and perihepatitis (Shivaprasad, 2000).

The characteristic gross lesions in salmonellosis affected birds include friable liver with bronze discoloration, white focal necrosis on liver, congested, haemorrhagic and discolored egg follicles with stalk formation, haemorrhagic to catarrhal enteritis, severely congested pneumonic lungs, enlarged and discolored spleen (Saha et al., 2012).

\section{Diagnosis}

A definitive diagnosis of fowl typhoid and pullorum disease requires the isolation and identification of $S$. gallinarum and $S$. pullorum, respectively. However, a tentative diagnosis can be made, based on the flock history, clinical signs, mortality and lesions. Positive serological findings can also be of great value in detection of infection (Shivaprasad, 2000).

\section{Collection of samples}

Since fowl typhoid and pullorum disease are systemic diseases, especially in young chicks and poults, these bacteria can be isolated from most of the body tissues. Liver, spleen, yolk sac, caeca are preferred organs for culture and lesions may also occur in the heart, gizzard, pancreas and lungs which are also suitable specimens for isolation (Shivaprasad, 2000). Cloacal swabs, fresh faeces from live birds, intestinal contents, egg shells, egg contents, embryos can also be used for isolation of $S$. pullorum and S. gallinarum (OIE, 2012).

\section{Isolation and Identification}

Samples collected from birds were inoculated into non selective enrichment (buffered peptone water) or selective enrichment broths such as tetrathionate, selenite cysteine and $\mathrm{F}$ broths. Enriched samples were cultured into selective media such as MacConkey agar, Xylose lysine deoxycholate (XLD) agar, Brilliant green agar (BGA) for isolation (OIE, 2012).

Colonies of $S$. Gallinarum on non-selective media are round, translucent, glistening, domed, smooth, and 1-2 $\mathrm{mm}$ in diameter after 24-48 hours incubation. Salmonella pullorum 
colonies are slightly smaller and translucent. On selective media their appearance varies with the medium (OIE, 2012).

Salmonella pullorum and S. gallinarum are non-motile and usually stained as gram negative, rod shaped appearance on Gram staining (Islam et al., 2006 and Saha et al., 2012). Biochemical tests such as urea hydrolysis, lysine decarboxylation, ornithine decarboxylation, maltose fermentation, dulcitol fermentation, inoculation into Triple sugar iron (TSI) agar for acid and gas production were carried out for identification of S. gallinarum and S. pullorum (OIE, 2012). Both organisms can ferment arabinose, dextrose, galactose, mannitol, mannose, rhamnose and xylose to produce acid with or without gas production (Christensen et al., 1992).

\section{Molecular diagnosis}

Plasmid profiling and ribotyping of $S$. gallinarum isolated from commercial layers and scavenging local chickens revealed prevalence of 18.4 and 2.6 per cent respectively (Mdegela et al., 2000). Oliveira et al., (2002) used polymerase chain reaction combined with Rappaport-Vassiliadis selective enrichment broth (PCR-RV) for detection of S. gallinarum and S. pullorum in poultry.

Inv A gene specific PCR (Malmarugan et al., 2011) and Multiplex PCR (Saravanan et al., 2012) were used for detection of Salmonella spp. in chicken samples. Prevalence of Salmonella infection in poultry tissue and egg samples by PCR revealed 2.7 per cent in Ethiopia (Menghistu et al., 2011).

\section{Economic losses}

Pullorum disease and fowl typhoid are economically important diseases, without their effective control through organised national regulatory programs, the profitable production of poultry is impossible (Willams, 1978). Principal current economic significance of $S$. pullorum in developed nations is the cost of testing programs, reminders of the potential for catastrophic losses have been provided by occasional appearance of pullorum disease in commercial flocks (Gast, 1997 b).

\section{References}

Barrow, P.A. and O.C. Freitas Neto, 2011. Pullorum disease and fowl typhoid new thoughts on old diseases: a review. Avian Pathol., 40: 1-13.

Barrow, P.A., A. Berchieri, O. Al-Haddad, 1992. Serological response of chickens to infection with Salmonella gallinarum-Salmonella pullorum detected by enzyme linked immunosorbent assay. Avian Dis., 36: 227-236.

Bhattacharjee, P.S., R.L. Kundu, J.U. Mazumder, E. Hossain, A.H. Miah, 1996. Retrospective analysis of chicken diseases diagnosed at the Central Disease Investigation Laboratory, Dhaka, Bangladesh. Bangladesh Vet. J., 30: 105-113.

Bouzoubaa, K., K. Lemainguer, J.G. Bell, 1992. Village chickens as a reservoir of Salmonella Pullorum and Salmonella Gallinarum in Morocco. Prev. Vet. Med., 12: 95-100.

Bumstead, N. and P. Barrow, 1993. Resistance to Salmonella Gallinarum, $S$. Pullorum and $S$. enteritidis in inbred lines of chickens. Avian Dis., 37:189193.

Christensen, J.P., J.E. Oslen, H.C. Hansen, and M. Bisgaard, 1992. Characterization of Salmonella enterica serovar gallinarum and pullorum by 
plasmid profiling and biochemical analysis. Avian Pathol., 22: 725-738.

Gast, R.K., 1997 a. Paratyphoid infections, In. Calnek, B.W., H.J. Barnes, C.W. Beard, L.R. McDoughald and Y.M. Saif (ed.), Diseases of poultry. $10^{\text {th }}$ edn, Iowa State University press, Ames, Iowa, USA, pp.97-121.

Gast, R.K., 1997 b. Detecting infections of chickens with recent Salmonella Pullorum isolates using standard serological methods. Poult.Sci., 76: 1723.

Grimont, P.A.D. and F.X. Weill, 2007. Antigenic formulae of the Salmonella Serovars, $9^{\text {th }}$ edn, World Health Organization Collaborating Centre for Reference and Research on Salmonella. Institute Pasteur, France, pp. 30-58.

Hutt, F.B. and R.D. Crawford, 1960. On breeding chicks resistant to pullorum disease without exposure thereto. Can. J. Genet. Cytol., 2: 357-370.

Islam, M.M., M.G. Haider, E.H. Chowdhury, M. Kamruzzaman and M.M. Hossain, 2006. Seroprevalence and pathological study of Salmonella infections in layer chickens and isolation and identification of causal agents. Bangl. J. Vet. Med., 4: 79-85.

Javed, T. and A. Hameed, 1989. Prevalence of Salmonella carriers among broiler breeders in Pakistan. Veterinarski Arhiv., 59: 185-191.

Jha, V.C., R.P. Thakur, K. Chand-Thakuri and J.N. Yadav, 1994. Prevalence of salmonellosis in chickens in the eastern Nepal. Veterinary Review Kathmandu, 9: 4-6.

Kumar, R., S. Sazawal, A. Sinha, S. Sood and M.K. Bhan, 1997. Typhoid fever: contemporary issues as related to the disease in India. Round table conference series on water borne diseases. $12^{\text {th }}$ edn, Ranbaxy science foundation, New Delhi. pp. 3-16.
Malmarugan, S., V. Thenmozhi and J.Johnson Rajeswar, 2011. Inv A gene specific PCR for detection of Salmonella from broilers. Vet. World, 4: 562-564.

Mdegela, R.H., M.G.S. Yongolo, U.M. Minga and J.E. Olsen, 2000. Molecular epidemiology of Salmonella gallinarum in chickens of Tanzania. Avian pathol., 29: 457-463.

Menghistu, H.T., R. Rathore, K. Dhama and R.K. Agarwal, 2011. Isolation, Identification and Polymerase Chain Reaction (PCR) Detection of Salmonella Species from field materials of poultry origin. Int. J. Microbiol. Res., 2: $135-142$.

Nazir, S., S.A. Kamil, M.M. Darzi, M.S. Mir, K. Nazir and A. Amare, 2012. Pathology of spontaneously occurring salmonellosis in commercial broiler chickens of Kashmir valley. J. World Poult. Res., 2: 63-69.

OIE, 2006. Salmonellosis, Office International des Epizooties. http: www.oie.int/chapter X.4.T

OIE, 2012. Fowl typhoid and Pullorum disease. In: Manual of diagnostic tests and vaccines, $7^{\text {th }}$ edn., Paris, France.

Oliveira, S.D., L.R. Santos, D.M.T. Schuch, A.B. Silva, C.T.P. Salle and C.W. Canal, 2002. Detection and identification of Salmonellas from poultry related samples by PCR. Vet. Microbiol., 87: 25-35.

Oystein, A., M.N. Skov, M. Chriel, J.F. Agger and M. Bisgaard, 1996. A retrospective study on Salmonella infection in Danish broiler flocks. Prev. Vet. Med., 26: 223237.

Rahman, M.A., M.A. Samad, M.B. Rahman and S.M.L Kabir. 2004. Bacteriopathological studies on salmonellosis, colibacillosis and pasteurellosis in natural and experimental infections in chickens. Bangladesh J. Vet. Med., 2:18. 
Rajagopal, R. and M. Mini, M. 2013. Outbreaks of salmonellosis in three different poultry farms of Kerala, India. Asian Pacific J. Trop. Biomed., 3: 496500.

Rosu, V., M.S. Chadfield, A. Santona, J.P. Chriistensen, L.E. Thomsen, S. Rubino and J.E. Olsen, 2007. Effects of crp deletion in Salmonella enterica serotype Gallinarum. Acta Veterinaria Scandinavica, 49:14.

Saha, A.K., M.A. Sufian, M.I. Hossain and M.M. Hossain, 2012. Salmonellosis in layer chickens: pathological features and isolation of bacteria from ovaries and inner content of laid eggs. $J$. Bangladesh Agr. Univ., 10: 61-67.

Saravanan, S., V. Purushothaman and T.R. Gopalakrishnamurthy, 2012. Multiplex PCR assay for the rapid detection of Salmonella in poultry and its related products. Indian J. Comp. Microbiol. Immunol. Infect. Dis., 33: 45-51.

Selvam, A., L. Gunaseelan, K. Senthilkumar and M. Sekar. 2010. Assessment of carrier status of Salmonella pullorum and gallinarum infection in healthy flocks. Tamilnadu J. Vet. Anim. Sci., 6: 99-101.

Shivaprasad, H.L., 2000. Fowl typhoid and pullorum disease. Rev. Sci. Techn. Off. Int. Epiz., 19: 405-424.

Shivaprashad, H.L., 1997. Pullorum disease and fowl typhoid. In: Calnek, B.W., H.J. Barnes, C.W. Beard, L.R. McDoughald and Saif, Y.M. (ed.), Diseases of Poultry, $10^{\text {th }}$ edn., Iowa State University press: Ames, Iowa, USA. pp. 82-96.

Williams, R.B., 1992. Differences between the anticoccidial potencies of monensin in maize-based or wheat-based chicken diets. Vet. Res. Commun., 16: 147-152.

\section{How to cite this article:}

Geetha, M. and Palanivel, K.M. 2018. A Brief Review on Salmonellosis in Poultry. Int.J.Curr.Microbiol.App.Sci. 7(05): 1269-1274. doi: https://doi.org/10.20546/ijcmas.2018.705.153 